\title{
Electrodeposition of Prussian Blue/Carbon Nanotube Composites at a Liquid-Liquid Interface
}

\author{
Samantha Husmann, ${ }^{a, b}$ Samuel G. Booth, ${ }^{b}$ Aldo J. G. Zarbin ${ }^{*, a}$ and Robert A. W. Dryfe ${ }^{*, b}$ \\ ${ }^{a}$ Grupo de Química de Materiais, Departamento de Química, Universidade Federal do Paraná, \\ CP 19081, 81531-980 Curitiba-PR, Brazil \\ ${ }^{b}$ School of Chemistry, University of Manchester, Oxford Road, M13 9PL Manchester, UK
}

\begin{abstract}
The iron complex hexacyanoferrate $\left(\mathrm{Fe}_{4}\left[\mathrm{Fe}(\mathrm{CN})_{6}\right]_{3}\right)$, known as Prussian Blue (PB), was electrodeposited over a free-standing carbon nanotube (CNT) film assembled at the interface between two immiscible liquids, water and 1,2-dichlorobenzene. Polarization of the interface achieved through a fixed potential or under potential variation enabled iron present inside CNTs to generate a stable CNT/PB composite. We report herein on the observation that the deposition of $\mathrm{PB}$ is dependent on both the $\mathrm{pH}$ and applied potential. It was found that aqueous phases containing $\mathrm{K}_{3}\left[\mathrm{Fe}(\mathrm{CN})_{6}\right]$ can decompose under an applied potential, while those containing $\mathrm{K}_{4}\left[\mathrm{Fe}(\mathrm{CN})_{6}\right]$ presented more stable behavior making it a suitable precursor for PB synthesis. The electrodeposition and modification of the interface was followed by in situ spectroelectrochemical Raman spectroscopy, which indicated that an increase in signal due to PB formation was acompanied by changes in the CNT bands due to modification of the CNT walls by decoration with PB, forming a composite structure.
\end{abstract}

Keywords: liquid-liquid interface, Prussian Blue, carbon nanotubes, immiscible liquids

\section{Introduction}

Biphasic liquid/liquid (L/L) systems have been used for a long time, either for the study of interfacial electron and ion transfer reactions or for the synthesis and assembly of micro and nano-sized materials. ${ }^{1,2}$ The interface between two immiscible liquids provides a defect-free environment suitable for controlled homogeneous particle deposition. Driven by the decrease in the L/L interfacial free energy, particles dispersed or synthesized in a biphasic system spontaneously migrate to the interface formed by the two liquids. ${ }^{3-5}$ Due to the ease of formation and robust nature of $\mathrm{L} / \mathrm{L}$ interfaces, they have been utilized in a wide range of different applications. The L/L system can be used simply as a means to assemble previously synthesized materials into organized arrays or thin films, such as carbon nanostructures or metal nanoparticles. ${ }^{6,7}$ Alternatively, materials can be both synthesized and assembled by using the $\mathrm{L} / \mathrm{L}$ interface as the region of contact between reactants located in the different phases. ${ }^{8-10}$ As an alternative to spontaneous reactions occurring at the point of contact

*e-mail: aldozarbin@ufpr.br; robert.dryfe@manchester.ac.uk This paper is part of the PubliSBQ Special Issue "IUPAC-2017" (http://publi.sbq.org.br/). between the two phases, material deposition can also occur by electrochemical polarization of the interface. ${ }^{11,12}$ In addition to standard synthetic parameters such as concentration, time or $\mathrm{pH}$, the applied potential and polarization of the interface between the two immiscible electrolyte solutions (ITIES) governs the rate of ion and electron transfer between the phases, allowing significant control over synthetic procedures. ${ }^{1,2,13,14}$ By combining these different approaches to utilize the $\mathrm{L} / \mathrm{L}$ interface, composite structures can be prepared using one material as the support and/or nucleation site for the other. ${ }^{15,16}$ Previously, it has been observed that particle or polymer formation was possible, under stirring, on the surface of carbon nanostructures present in a $\mathrm{L} / \mathrm{L}$ system. ${ }^{17,18}$ However, greater control can be achieved if the material is initially assembled and supported at the $\mathrm{L} / \mathrm{L}$ interface, prior to the synthesis of the second component through either spontaneous or polarization driven reactions. This method allows thickness control and even asymmetric functionalization of the adsorbed films..$^{19,20}$

Thin films of composite materials with carbon nanostructures such as carbon nanotubes (CNTs) have a wide range of applications, especially regarding energy storage/conversion devices and optoelectronics. ${ }^{21-23}$ 
Nevertheless, composite processing and deposition as thin films has still to be fully resolved as control over thickness, conductivity and transparency have not yet been completely developed. In many cases, CNT composites are produced by modification of CNT electrodes with electrochemically active species, which is the case for Prussian Blue (PB) based composites. PB has the general formula $\mathrm{Fe}^{\mathrm{III}}{ }_{4}\left[\mathrm{Fe}^{\mathrm{II}}(\mathrm{CN})_{6}\right]_{3} \cdot \mathrm{xH}_{2} \mathrm{O}$ and is part of the class of compounds known as hexacyanometallates (HCM) ${ }^{24,25}$ With a porous face-centered cubic structure and electrochemically active metal centers, PB and most of the HCMs have as many potential fields of application as CNTs. In fact, CNT/HCM composites have been applied in sensors, membranes, electrochromic devices, batteries and catalysts, among others. ${ }^{26-30} \mathrm{HCMs}$, however, usually present low chemical and electrochemical stability, which can be improved by CNTs in CNT/HCM composites. ${ }^{31}$ The better the interaction between the materials, the higher their stability. ${ }^{32,33}$ Some of the authors of the present work have been developing a different approach to synthesize CNT/PB composites through a heterogeneous reaction between $\mathrm{K}_{3}\left[\mathrm{Fe}(\mathrm{CN})_{6}\right]$ in aqueous solution and solid iron species present inside CNT cavities. ${ }^{34}$ Through this route, nanocubes of PB are formed directly over the CNTs, decorating their walls, and presenting high electrochemical stability. This was also shown to be true for other CNT/HCM composites obtained by this method. ${ }^{35-37}$ The electrodeposition of PB (or other $\mathrm{HCMs}$ ) over CNTs requires the electrodes to be, at least to some extent, conductive. This condition restricts the type of substrates over which the CNT electrodes may be prepared and therefore their application and/or device configurations. The use of an ITIES to perform PB electrodeposition over CNTs assembled at the L/L interface would allow for the formation of a complete composite, free from any substrate, expanding the possible applications of this material. In this work, we report on the electrochemical deposition of PB over an iron-filled CNT thin film, assembled at a L/L interface. The reaction is driven by positive polarization of the aqueous phase solution. Although PB was already observed during $\mathrm{L} / \mathrm{L}$ electron transfer studies with hexacyanoferrate, no controlled electrodeposition of $\mathrm{PB}$ or PB composites have been described thus far. ${ }^{38-40}$

\section{Experimental}

\section{Chemicals}

The following chemicals and solvents were purchased for this work and used without further purification: potassium ferricyanide (Sigma-Aldrich, $>99 \%$ ), potassium ferrocyanide (Sigma-Aldrich, > 98.5\%) lithium chloride
(Sigma-Aldrich, > 99\%), bis (triphenylphosphoranylidene) ammonium chloride (BTPPACl, Sigma-Aldrich, > 98\%), sodium tetrakis(4-fluorophenyl)borate dihydrate (NaTFPB, Alfa Aesar, > 97\%), toluene (Sigma-Aldrich, > 99\%), 1,2-dichlorobenzene (DCB, Aldrich, >99\%), trifluoracetic acid (TFA, Vetec, $>98 \%$ ), sulfuric acid (Sigma-Aldrich, > 98\%), nitric acid (Sigma-Aldrich, $>35 \%$ ) and hydrochloric acid (Sigma-Aldrich, > 99\%). Bis(triphenylphosphoranylidene) ammonium tetrakis(4-fluorophenyl)borate (BTPPATFPB) was synthesized by the mixture and recrystallization of BTPPACl and NaTFPB as described elsewhere. ${ }^{41-43}$ All aqueous solutions were prepared with ultrapure water (Milli-Q, 18.2 $\mathrm{M} \Omega$ cm resistivity).

\section{Carbon nanotube film preparation}

Iron-filled multi-walled (MW) CNTs were synthesized according to previous reports. ${ }^{44}$ In summary, $0.7 \mathrm{~g}$ of ferrocene were positioned in a quartz tube placed inside a two-region tubular furnace. The first region was heated up to $300^{\circ} \mathrm{C}$ and the sublimed ferrocene was carried by an argon flow to the second region held at $900^{\circ} \mathrm{C}$, where CNT growth takes place. Before use, $20.0 \mathrm{mg}$ of the as-prepared CNTs were treated with $5 \mathrm{~mL}$ of trifluoroacetic acid in $50 \mathrm{~mL}$ of toluene and placed in an ultrasonic bath for $2 \mathrm{~h}$, to remove impurities. After treatment, the CNT dispersions were centrifuged (3500 rpm, four times, each time for $10 \mathrm{~min}$ ), the isolated solid was washed and dried at $80^{\circ} \mathrm{C}$. The film was prepared through $\mathrm{L} / \mathrm{L}$ interfacial assembly as reported elsewhere. ${ }^{17} \mathrm{~A}$ mass of $0.30 \mathrm{mg}$ of the CNTs were dispersed in $20 \mathrm{~mL}$ of toluene using a probe ultrasound (Cole-Palmer) for $10 \mathrm{~min}$ at $40 \%$ amplitude with pulses of $50 \mathrm{~s} / 10 \mathrm{~s}$ (on/ off). The dispersion was then stirred with $20 \mathrm{~mL}$ of ultrapure water in a $50 \mathrm{~mL}$ round bottom flask for at least $2 \mathrm{~h}$. Once stirring was stopped, a continuous CNT film was observed at the $\mathrm{L} / \mathrm{L}$ interface. In order to use the film in the four electrode cell for interfacial electrodeposition, the organic phase was exchanged for DCB. Toluene was completely removed from the system with a pipette, forming a water/air interface. Subsequently, $20 \mathrm{~mL}$ of DCB was added forming a new L/L interface with the CNT film assembled between the aqueous and organic electrolyte solutions. For control experiments, hollow (non Fe-filled) CNTs were obtained by arc discharge. The procedures for film preparation and transfer to a $\mathrm{L} / \mathrm{L}$ interface were the same as described for Fe-filled CNTs.

\section{Electrochemical measurements}

A four-electrode setup was applied using a homemade three-arm glass cell with Luggin capillaries to connect the bulk solution to the reference electrodes. The cell 


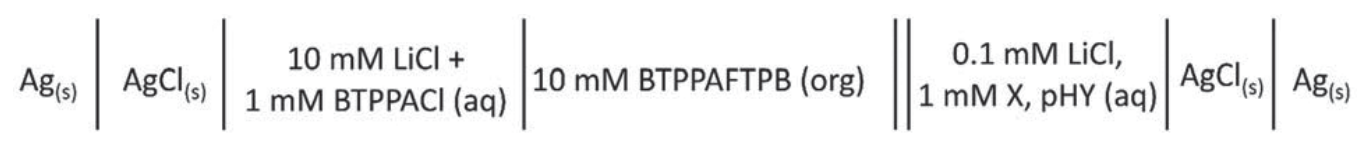

Scheme 1. Setup of the liquid-liquid electrochemical cell.

volume was approximately $4 \mathrm{~mL}$. Homemade $\mathrm{Ag} / \mathrm{AgCl}$ reference electrodes and $\mathrm{Pt}$ mesh counter electrodes were used for both organic and aqueous phases. The general composition of the cell is given in Scheme 1. Unless stated otherwise, BTPPATFPB $\left(10 \mathrm{mmol} \mathrm{L}^{-1}\right)$ in DCB was used as the organic electrolyte solution. A reference interface was created for the organic phase by placing an aqueous solution of $1 \mathrm{mmol} \mathrm{L}^{-1}$ BTPPACl and $10 \mathrm{mmol} \mathrm{L}^{-1} \mathrm{LiCl}$ on top of the organic phase within the arm of the organic Luggin capillary. A $0.1 \mathrm{~mol} \mathrm{~L}^{-1} \mathrm{LiCl}$ solution was used as a standard aqueous supporting electrolyte with different media depending on the study. Acidic solutions were prepared with $\mathrm{HNO}_{3}: \mathrm{H}_{2} \mathrm{SO}_{4}(1: 1)$ at different $\mathrm{pH}$ values. For PB deposition, $1 \mathrm{mmol} \mathrm{L}^{-1} \mathrm{~K}_{3}\left[\mathrm{Fe}(\mathrm{CN})_{6}\right]$ or $\mathrm{K}_{4}\left[\mathrm{Fe}(\mathrm{CN})_{6}\right]$ was included in the aqueous phase. The setup was prepared so that the aqueous/organic interface was positioned between the two Luggin capillaries. For the measurements with CNTs, the previously prepared film (see section above) was placed at the interface with a pipette (Figure 1).

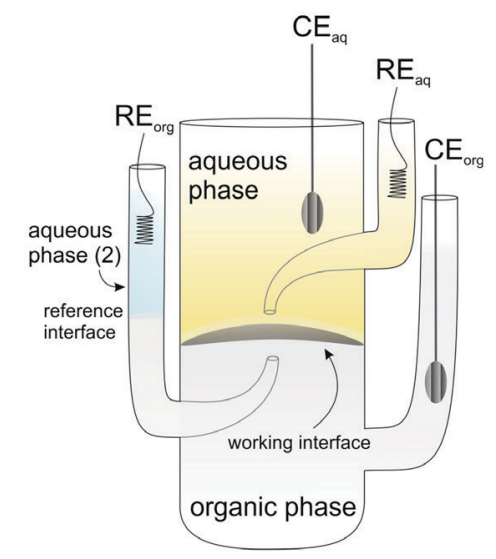

Figure 1. Four-electrode electrochemical cell used in the experiments.

\section{Equipment}

Standard electrochemical measurements were performed with an Autolab PGSTAT100 (Metrohm), while the electrochemistry performed during in situ Raman spectroelectrochemical measurements was conducted on an EmStat3 (PalmSens). Raman spectra were acquired using a Renishaw inVia Raman microscope (RE04) with a $\mu \mathrm{m}$ scale resolution stage-controlled sample holder, coupled with a $633 \mathrm{~nm}(1.96 \mathrm{eV})$ laser operating at $32 \mathrm{~mW}$ power using a $20 \times$ objective. Scanning electron microscopy (SEM) images were obtained with a Quanta 650 FEG microscope (ThermoFisher Scientific) at an accelerating voltage of $15 \mathrm{kV}$.

\section{Results and Discussion}

As covered in the Introduction section, the synthetic method utilized in this work is dependent on the iron species present within the CNT cavities. In order to form $\mathrm{PB}$, the metal species must first be extracted from the CNTs so that they can react with the other precursor, potassium hexacyanoferrate, in the aqueous solution, as follows:

$\mathrm{K}^{+}+\mathrm{Fe}^{2+}+\left[\mathrm{Fe}(\mathrm{CN})_{6}\right]^{3-} \rightarrow \mathrm{KFe}\left[\mathrm{Fe}(\mathrm{CN})_{6}\right]$

In the absence of the iron species, PB cannot be synthesized. ${ }^{34-37}$ In a conventional three-electrode system, either an electrochemical overpotential or acidic media can promote the extraction of the iron species from the CNTs. Previously, CNT films were modified with PB at pH 7 through cyclic voltammetry over a range between -0.3 and $1.4 \mathrm{~V} .{ }^{35} \mathrm{At}$ lower $\mathrm{pHs}$, a narrower window can be applied, although the amount of material formed is directly dependent on both anodic and cathodic potentials, as well as the solution $\mathrm{pH}$. As an example of this behavior, cyclic voltammograms of CNT films deposited over indium tin oxide (ITO) substrates were acquired using different $\mathrm{pHs}$ and potential scan ranges (Supplementary Information (SI), Figure S1). The appearance and growth of the redox process associated with the transition between $\mathrm{PB}$ and its oxidized form, Berlin Green (BG), at $\Delta \varphi_{1 / 2}$ ca. $0.74 \mathrm{~V}$ is a characteristic sign of $\mathrm{PB}$ electrodeposition over the film. The cyclic voltammograms given in Figure S1 show the effect of the experimental conditions on the formation of the material. If an insufficiently oxidizing potential is applied to the system at a given $\mathrm{pH}$, the iron species from the CNTs do not leave the cavities thus no PB is produced. In the same way, lowering the $\mathrm{pH}$ increases the amount of material formed under a given potential range. It is worth noting that oxidative potentials promote the exit of metal species by oxidation, having a stronger effect on the synthesis. However, if the reductive potential applied is not sufficiently high the PB formation is also severely compromised.

In the 4-electrode system, the potential window is limited by the transfer of supporting electrolyte ions across the interface. A wider potential window can be achieved 
with highly hydrophobic organic and hydrophilic aqueous salts in solution. ${ }^{45}$ In this sense, both $\mathrm{LiCl}$ and BTPPATFPB are well established aqueous and organic electrolytes, respectively. The choice of the organic solvent also changes the working window since it affects the affinity of electrolytes from both phases. ${ }^{15,16,46}$ Relative permittivity, miscibility in water and solubility of the organic electrolytes are a few parameters to consider. Despite its toxicity, DCB is widely applied for studies at the ITIES, presenting stable potential windows up to $1.1 \mathrm{~V}$ and therefore was chosen as the organic phase in the present work. ${ }^{47}$ Because DCB can decompose and polymerize under mild sonication conditions, CNTs could not be directly assembled at the cell interface by the ultrasound-induced adsorption typically applied for ITIES studies ${ }^{48,49}$ For this reason, the films of CNTs were previously prepared by the interfacial method in toluene and then the organic phase was exchanged to DCB prior to the cell set up (see Experimental section). ${ }^{6,7}$

The potential window of the system was evaluated before studies of electrodeposition were undertaken. As a convention for ITIES, the polarization of the interface is defined with respect to the aqueous phase. This means that positive polarization indicates that the aqueous phase is more positive than the organic one, and the contrary holds for negative polarization. If the potentials extend sufficiently towards the negative and positive directions, transfer of the electrolyte ions starts to occur, as observed in Figure S2 (SI section) by the increase of the current at both limiting potentials. At positive polarization, the process refers to the transfer of $\mathrm{Li}^{+}$ions from the aqueous phase or $\mathrm{TFPB}^{-}$from the organic phase to their respective opposing phases. At negative polarization, the transfer takes place with $\mathrm{Cl}^{-}$and $\mathrm{BTPPA}^{+}$from the aqueous and organic phases, respectively. ${ }^{1-5,50}$ The presence of the CNTs at the interface increases the current in the voltammetry, as observed in Figure 2. This increase in current could be related to the presence of the Fe species within the CNTs, as no such increase in background current was observed in a previous study with CNTs (single-walled type) adsorbed at the L/L interface. ${ }^{51}$ It is well known that particle confinement in CNTs can result in an enhanced catalytic performance and increased capacitive currents. ${ }^{52,53}$ Catalysis towards hydrogen reduction was also observed for CNTs assembled at a $\mathrm{L} / \mathrm{L}$ interface containing metal impurities. ${ }^{54}$ Since the SWCNT adsorbed at the ITIES in the work of Toth et al. ${ }^{51}$ did not contain such particles, it seems reasonable to assume the metallic species are responsible for the changes in the electrochemical profile. A broadening of the electrolyte ion transfer limiting the potential window is also seen in the presence of CNTs, indicating that their presence inhibits this process at the interface. ${ }^{55}$

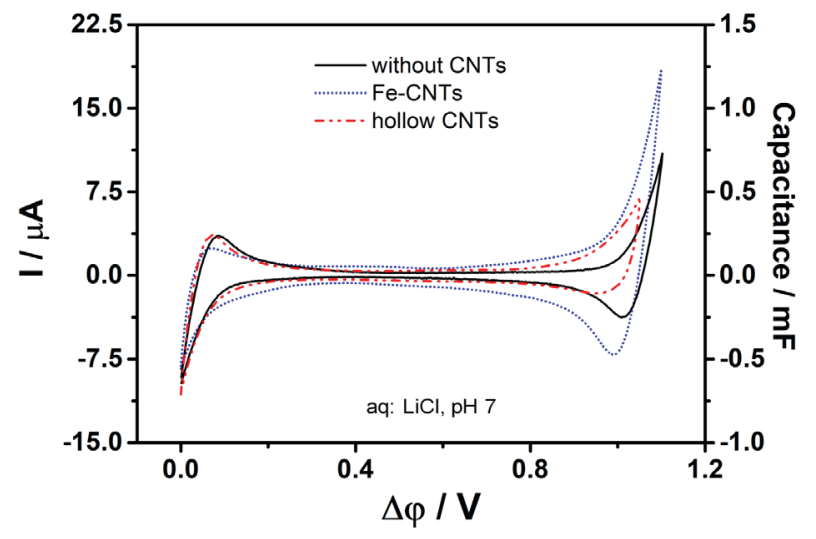

Figure 2. Cyclic voltammograms of the water/DCB interface in the presence and absence of CNTs assembled at the inteface. Aqueous phase contains $\mathrm{LiCl}\left(0.1 \mathrm{~mol} \mathrm{~L}^{-1}\right)$. Scan rate $15 \mathrm{mV} \mathrm{s}^{-1}$. The interfacial capacitance is shown on the right-hand axis, although the values are only relevant for the central part of the voltammogram where minimal Faradaic currents flow.

For PB electrodeposition at the L/L interface, $1.0 \mathrm{mmol} \mathrm{L}^{-1} \mathrm{~K}_{3}\left[\mathrm{Fe}(\mathrm{CN})_{6}\right]$ was added to the aqueous phase. Due to the narrower useful potential window when compared with the 3-electrode system, lower $\mathrm{pHs}$ were tested for the modification of CNTs. ${ }^{35-37}$ Figure 3a presents the voltammograms obtained at $\mathrm{pH} 4$. It is possible to observe the evolution of several redox peaks which are seen to increase in current on repeat cycling. A reversible process occurs at $\Delta \varphi_{1 / 2}$ ca. $0.65 \mathrm{~V}$ (identified as I in Figure $3 \mathrm{~b}$ ), and at 0.93 and $0.15 \mathrm{~V}$ (identified as II and III in Figure 3b, respectively), two different signals appear at positive and negative polarization, respectively. Without CNTs, the voltammetric profile remains essentially the same during cycling, indicating that these signals arise from the presence of CNTs (Figure S3a, SI section).

To evaluate the effect of the $\mathrm{K}_{3}\left[\mathrm{Fe}(\mathrm{CN})_{6}\right]$ on this behavior, the same experiment was performed without this species present, i.e., using a "blank" aqueous solution $\left(0.1 \mathrm{~mol} \mathrm{~L}^{-1} \mathrm{LiCl}\right)$. With slight shifts of the redox signals, the voltammetric profile remains the same when CNTs undergo several cycles in acidic media (Figure 3b). In this case, the observed signals must arise from CNTs assembled at the interface since the bare interface does not show the same profile during the cycles (Figure 3c). The profile was initially assigned to the release or oxidation of the iron species from the CNTs. However, further investigations with hollow CNTs (no metal species) presented the same profile (Figures S3c and S3d, SI section). As will be discussed later, no spectroscopic changes are observed in the CNT bands in the absence of PB formation and while cycling in $0.1 \mathrm{~mol} \mathrm{~L}^{-1} \mathrm{LiCl}$ aqueous solution. Consequently, if the redox profile observed here relates to the oxidation or any possible functionalization of the 

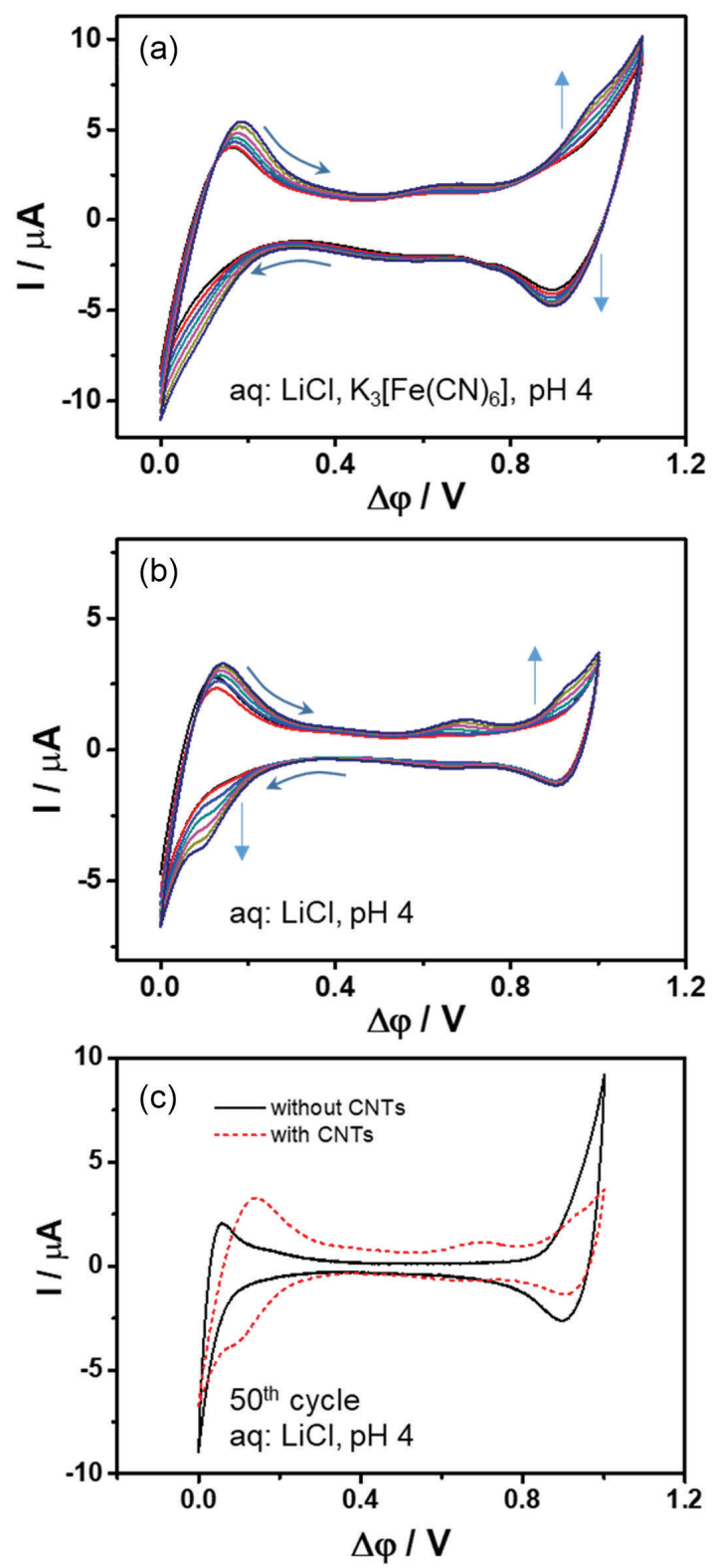

Figure 3. Cyclic voltammograms of the water/DCB interface with assembled CNTs. Aqueous phase (a) $0.1 \mathrm{~mol} \mathrm{~L}^{-1} \mathrm{LiCl}$ and $1 \mathrm{mmol} \mathrm{L}^{-1}$ $\mathrm{K}_{3}\left[\mathrm{Fe}(\mathrm{CN})_{6}\right]$ at $\mathrm{pH} 4$, scan rate $50 \mathrm{mV} \mathrm{s}^{-1}$; (b and c) $0.1 \mathrm{~mol} \mathrm{~L}^{-1} \mathrm{LiCl}$ $\mathrm{pH} \mathrm{4}$, scan rate $15 \mathrm{mV} \mathrm{s}^{-1}$; (c) $50^{\text {th }}$ cycle in the presence and absence of CNTs at the interface.

CNTs, due to the electrochemical potential, it occurs to a very low extent. At negative polarization, CNTs tend to de-aggregate, increasing their total surface area, which could increase the current of processes such as $\mathrm{NO}_{3}^{-}$(from $\mathrm{HNO}_{3}$ ) transfer from the aqueous to the organic phase. Yet, the other observed processes would not relate to this effect. Voltammetric responses similar to peaks II and III due to lithium intercalation in CNTs, which could occur due to $\mathrm{Li}^{+}$transfer from aqueous to organic phases at positive polarizations, ${ }^{56}$ have been described, however, the experiments conducted in this work cannot confirm this effect. Future work will be necessary to elucidate this electrochemical behavior.

The potential window accessible at the water/DCB interface did not permit electrodeposition of PB. Over these applied potentials, $\mathrm{pH} 4$ is not sufficiently acidic to extract the iron species from the CNTs in order to synthesize the composite. At lower pHs (2 and 3), $\mathrm{PB}$ was formed both in the presence and absence of CNTs, characterized by the appearance of a blue color at the interface. This occurs because $\mathrm{K}_{3}\left[\mathrm{Fe}(\mathrm{CN})_{6}\right]$ can decompose in strongly acid media. ${ }^{57-60}$ In addition, polarization of the interface promotes proton transfer from the aqueous to the organic phase, accelerating $\mathrm{K}_{3}\left[\mathrm{Fe}(\mathrm{CN})_{6}\right]$ decomposition, resulting in the deposition of PB on the surface of the CNTs.

From previous works, it is well established that the composite produced by the reaction between species in aqueous solution and metal species from CNT cavities have better electrochemical stability and enhanced performance in several applications, compared to the usual composite synthesis. ${ }^{35-37}$ This occurs precisely because one of the reactants necessary for $\mathrm{PB}$ synthesis comes from inside the CNTs, driving PB deposition on the CNT walls and optimizing the interaction between the composite components. Therefore, chemical synthesis of PB from $\mathrm{K}_{3}\left[\mathrm{Fe}(\mathrm{CN})_{6}\right]$ decomposition is likely to present poor stability and adhesion over the CNT film. In fact, when the aqueous phase is washed and exchanged with pure $\mathrm{LiCl}$ electrolyte solution, the blue color disappears from the interface, as it diffuses through the aqueous phase.

In contrast to $\mathrm{K}_{3}\left[\mathrm{Fe}(\mathrm{CN})_{6}\right], \mathrm{K}_{4}\left[\mathrm{Fe}(\mathrm{CN})_{6}\right]$ is much more stable in acidic media, especially if combined with supporting electrolyte counterions. ${ }^{61,62}$ Even though it can decompose under high exposure to UV light, if in high concentration, the timescale of decomposition is far longer than the electrodeposition of $\mathrm{PB}$, especially in the $\mathrm{mmol} \mathrm{L}^{-1}$ range used in these experiments. ${ }^{63}$ Yet, its decomposition does not generate free iron species, which are responsible for PB formation in the case of $\mathrm{K}_{3}\left[\mathrm{Fe}(\mathrm{CN})_{6}\right]$. With this consideration, the same experiments were performed using $1 \mathrm{mmol} \mathrm{L}^{-1} \mathrm{~K}_{4}\left[\mathrm{Fe}(\mathrm{CN})_{6}\right]$ and $0.1 \mathrm{~mol} \mathrm{~L}^{-1} \mathrm{LiCl}$ as aqueous electrolyte (Figure 4).

A similar voltammetric profile was observed to those in Figure 3, since the discussed signals arise from the presence of CNTs. Although no significant change is observed in the voltammetric profile during the cycles, PB was deposited, to different degrees, in all the acidic media in the presence of CNTs, characterized by a clear blue color at the interface, while no PB formation was noted in the absence of CNTs. Consequently, it can be concluded that under these conditions, iron species from CNTs became 


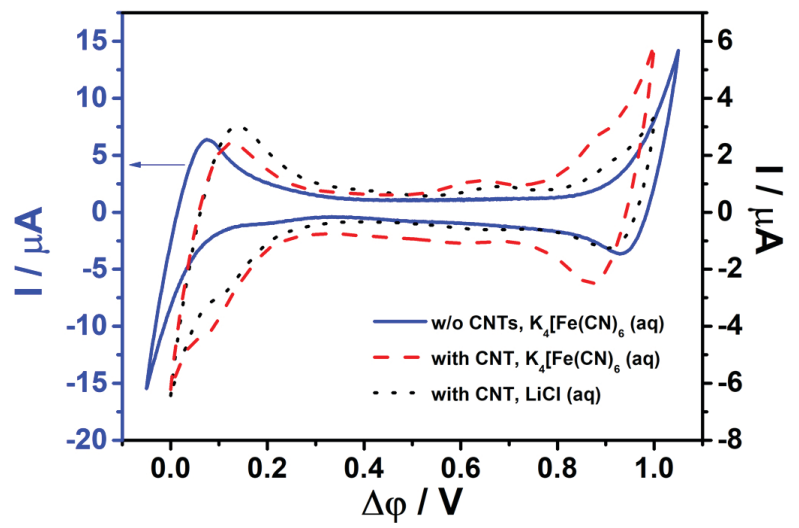

Figure 4. Fiftieth cyclic voltammetric scan of the water/DCB interface without (blue) and with (black, red) CNTs assembled at the interface using different aqueous phases specified in the figure.

available while no decomposition of $\mathrm{K}_{4}\left[\mathrm{Fe}(\mathrm{CN})_{6}\right]$ occurs, creating an ideal system for composite preparation.

In situ spectroelectrochemical Raman measurements were performed in order to generate a better understanding of, and further characterize, the composite formation at the L/L interface. PB has a broad absorption band with a maximum at around $680 \mathrm{~nm}$, presenting a resonance Raman effect when irradiated under a $633 \mathrm{~nm}$ laser. ${ }^{32,33,64}$ Therefore, this wavelength was chosen for the experiments to facilitate the observation of PB bands during its formation. The same electrochemical cell was used for these experiments, and an L-shaped adapter was used with the microscope objective so that the incident laser was parallel to the plane of the $\mathrm{L} / \mathrm{L}$ interface.

Prior to electrochemical deposition, the spectral response was studied normal to the interface by adjusting the cell height with respect to the laser spot (Figure 5). In a bare interface, formed only of organic and aqueous electrolytes, the z-depth profile shows bands corresponding to the DCB modes at 1275, 1379, 1457 and $1573 \mathrm{~cm}^{-1}$. As the laser tracks up through the interface, these bands are seen to decrease rapidly and then disappear once the laser reaches the aqueous phase, where no signal is present. When $\mathrm{K}_{4}\left[\mathrm{Fe}(\mathrm{CN})_{6}\right]$ is present in the aqueous phase, a small signal at $2132 \mathrm{~cm}^{-1}$ is observed within the meniscus of the L/L interface. However, with CNTs assembled at the interface, the profile changes significantly. In the studied range, three MWCNT bands can be observed (Figure 5a): the band at $1577 \mathrm{~cm}^{-1}$ (G band) corresponds to a typical graphite mode that arises from $\mathrm{sp}^{2}$ vibrations from the hexagonal arrangement of carbon atoms; the so-called D band, at $1333 \mathrm{~cm}^{-1}$, is a prohibited band that becomes active due to the loss of symmetry in this network, which is usually related to defects such as $\mathrm{sp}^{3}$ hybridized carbon atoms or incomplete bonding. Similarly, the shoulder at $1611 \mathrm{~cm}^{-1}$ (D' band) is associated with defects at the edge, or changes in the external wall, of multi-walled type CNTs. ${ }^{65-67}$ Concomitantly with the CNT signals, another set of bands are observed between 2000 and $2200 \mathrm{~cm}^{-1}$. These signals correspond to $\mathrm{C} \equiv \mathrm{N}$ stretching modes from the $\left[\mathrm{Fe}(\mathrm{CN})_{6}\right]^{4-}$ ions present in the aqueous phase. From higher to lower frequencies, they are assigned to $A_{1 g}, E_{g}, F_{1 g}$ and $\mathrm{F}_{2 \mathrm{~g}}$ modes from $\mathrm{O}_{\mathrm{h}}$ symmetry. ${ }^{68,69}$ The bands are only observed at the $\mathrm{L} / \mathrm{L}$ interface, in the presence of CNTs: when the CNT signal falls away, so do those due to the $\left[\mathrm{Fe}(\mathrm{CN})_{6}\right]^{4}$. Therefore, $\mathrm{CNTs}$ are enhancing $\mathrm{C} \equiv \mathrm{N}$ modes that are normally observed only in saturated solutions, while the studied system is within the $\mathrm{mmol} \mathrm{L}^{-1}$ range and far from saturation. The enhancement could arise from adsorption of the aqueous $\left[\mathrm{Fe}(\mathrm{CN})_{6}\right]^{4-}$ ions on the surface of CNTs at the L/L interface, which could also decrease the hydration sphere of the complex. ${ }^{70,71}$ In fact, a splitting of the $\mathrm{E}_{\mathrm{g}}$ mode of anhydrous $\mathrm{K}_{4}\left[\mathrm{Fe}(\mathrm{CN})_{6}\right]$ occurs, compared to the hydrated complex, that correlates with the $\mathrm{C} \equiv \mathrm{N}$ band profile observed in Figure 5.29,68

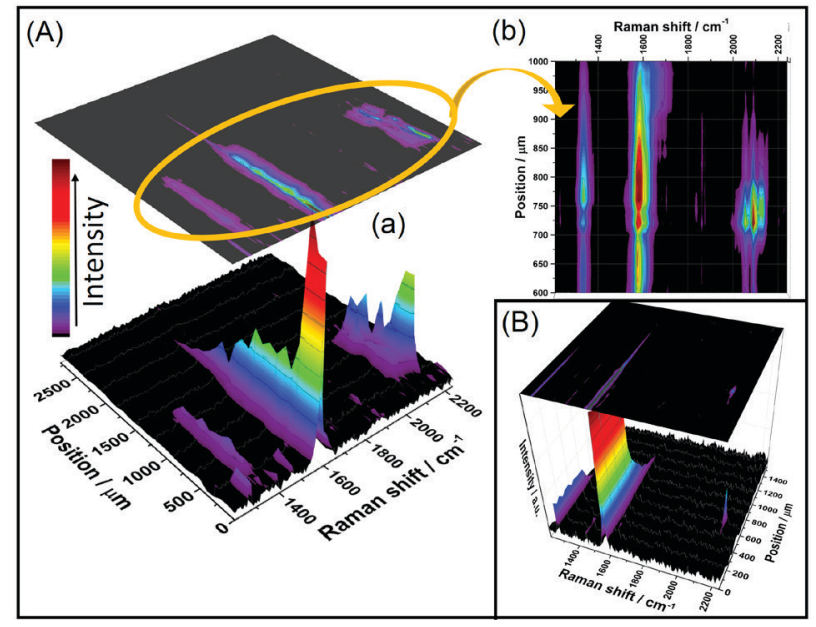

Figure 5. Depth profile from Raman spectra obtained at different height positions through the cell in the presence (A) and absence (B) of CNTs at the $\mathrm{L} / \mathrm{L}$ interface. (a) $3 \mathrm{D}$ view and (b) projection of the area indicated. Aqueous phase contains $\mathrm{LiCl}\left(0.1 \mathrm{~mol} \mathrm{~L}^{-1}\right)$ and $\mathrm{K}_{4}\left[\mathrm{Fe}(\mathrm{CN})_{6}\right]\left(1 \mathrm{mmol} \mathrm{L}^{-1}\right)$, pH 4.

To evaluate PB formation over the CNT film, the laser was focused directly onto the $\mathrm{L} / \mathrm{L}$ interface where the above-mentioned signals are present. The position of the $\mathrm{L} / \mathrm{L}$ interface can move under polarization as this alters the interfacial tension, and hence the curvature, of the meniscus. For that reason, it was not viable to monitor PB deposition through cyclic voltammetry, as the variation in the applied potentials results in a loss of the Raman signal from the interface when the laser spot is kept at a fixed position. At a fixed polarization potential, however, the interface position and curvature are quite stable and hence easier to monitor. For that reason, in situ spectroelectrochemical Raman 
measurements were performed with chronoamperometry at $1.1 \mathrm{~V}$.

Figure 6 shows Raman spectra acquired during chronoamperometric measurements. In the $3 \mathrm{D}$ projection of the data (Figure 6a), it is possible to observe that the signal from the $\mathrm{C} \equiv \mathrm{N}$ vibrational modes increase with time, as well as the D band intensity. In a closer examination of the projection data, a significant shift to higher frequencies occurs for $\mathrm{C} \equiv \mathrm{N}$ modes under the applied potential (Figure 6b and Figure S5, SI section). While present in an ionic species such as $\left[\mathrm{Fe}(\mathrm{CN})_{6}\right]^{4-}$, lower energy free $\mathrm{CN}^{-}$ modes are observed, whereas when the second metallic center coordinates to the ion via the nitrogen atom of the $\mathrm{CN}$ ligands to produce $\mathrm{PB}$, a rigid structure is formed, shifting CN modes to higher frequencies. ${ }^{56,68,69}$ The degree of defects and incomplete bonding also dictate the band positions. Therefore, the more ferric ions coordinate to $\mathrm{N}$ to form an organized cubic structure, the more $\mathrm{CN}$ modes shift. ${ }^{72-75}$ Interaction between CNTs and as-synthesized PB occurs mainly through p-doping of CNTs, which transfer electron density to the metal species of the complex through a $\pi-\pi$ interaction. ${ }^{76,77}$ As a result of the increased density, the $\pi$ back-bonding from cyano-ligands to the CNTs is enhanced, in turn improving the interaction between the materials. The decrease in electron density of $\mathrm{CN}$ due to $\pi$ back-bonding also shifts the $\mathrm{C} \equiv \mathrm{N}$ stretching modes to higher frequencies. ${ }^{32,33,64}$

The modification of the interface with $\mathrm{PB}$ can also be observed by spectroscopic changes to the CNTs. As discussed above, the D band correlates with the loss of symmetry in the graphitic $\mathrm{sp}^{2}$ network, due to the presence of defects. To evaluate the extent of these defects, the intensity ratio between the $\mathrm{D}$ band and $\mathrm{G}$ band, known as $\mathrm{I}_{\mathrm{D}} / \mathrm{I}_{\mathrm{G}}$, is calculated. ${ }^{32,33}$ During the electrodeposition experiment, $\mathrm{I}_{\mathrm{D}} / \mathrm{I}_{\mathrm{G}}$ goes from 0.40 at $\mathrm{t}=0.0 \mathrm{~s}$ to 0.57 after $2100 \mathrm{~s}$, when applying $1.1 \mathrm{~V}$. The significant increase of the D band intensity clearly indicates that the CNT walls are being modified by the deposition of PB. In the same way, PB formation and $\pi$ back-bonding interactions with the CNTs leads to an increase in "holes" on the CNTs, due to p-doping, shifting the $\mathrm{G}$ band to higher frequencies. ${ }^{32,33,78}$ In addition, a blue shift of $4 \mathrm{~cm}^{-1}$ is also observed for the $\mathrm{G}$ band during the experiment. When the polarization is applied in the absence of aqueous phase $\mathrm{K}_{4}\left[\mathrm{Fe}(\mathrm{CN})_{6}\right]$ (Figure 6d), no spectroscopic changes are observed for the CNTs, confirming that the rest of the spectral data discussed here arise from $\mathrm{PB}$ deposition.

As mentioned before, PB formation, especially at lower pHs, is characterized by a blue coloration of the L/L interface. Figure S6 (SI section) shows images after PB deposition, obtained with an optical microscope coupled to the Raman spectrometer. It is possible to observe that $\mathrm{PB}$ is preferentially formed at the aqueous side of the interface, where a blue coloration gradually disappears within the bulk phase, while a defined blue/ yellowish interface is observed at the surface of the DCB phase. After the deposition, the aqueous phase is washed and exchanged for a $\mathrm{LiCl}\left(0.1 \mathrm{~mol} \mathrm{~L}^{-1}\right)$ solution, and the depth profile of the cell was performed. In this system, it is still possible to observe $\mathrm{PB} \mathrm{C} \equiv \mathrm{N}$ modes at the same z-height as the modes corresponding to the CNTs, confirming composite formation and indicating that $\mathrm{PB}$ is well adhered to the CNT walls (Figure S7, SI section). As a confirmation of the electrodeposition of PB, both phases where washed to remove the electrolytes and the film was then transfered to an ITO substrate to perform SEM analysis (Figure 7). In these images, several small cubes can be observed decorating the walls of the CNTs. Although the quantity of PB produced by this route is lower than previously observed on solid CNT electrodes, these images confirm that indeed it is possible to electrodeposit PB at the $\mathrm{L} / \mathrm{L}$ interface.
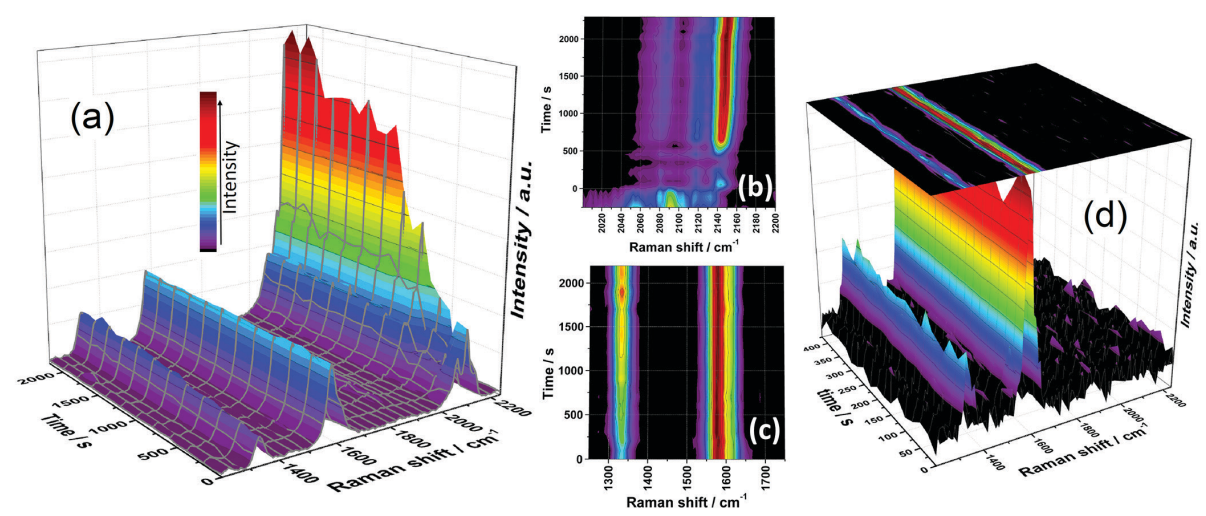

Figure 6. Raman spectra acquired at the water/DCB interface with CNTs assembled at the interface during chronoamperometry at $1.1 \mathrm{~V}$. Aqueous phase $\mathrm{LiCl}\left(0.1 \mathrm{~mol} \mathrm{~L}^{-1}\right)$ with $\left(\mathrm{a}, \mathrm{b}\right.$ and c) and without (d) $\mathrm{K}_{4}\left[\mathrm{Fe}(\mathrm{CN})_{6}\right]\left(1.0 \mathrm{mmol} \mathrm{L}^{-1}, \mathrm{pH} 4\right)$. (a) 3D data and projection of (b) CN and (c) CNTs modes; (d) 3D data with projection on top. 

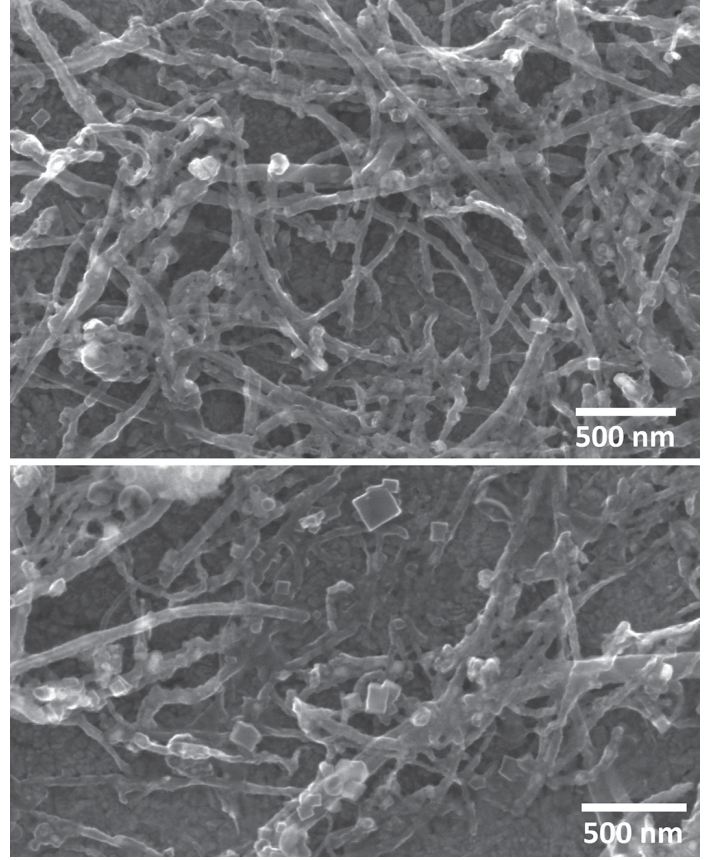

Figure 7. SEM images of the CNT/PB composite obtained at the L/L interface.

To confirm that the PB deposited under applied potential is synthesized from the reaction between the iron species from the CNTs and the $\mathrm{K}_{4}\left[\mathrm{Fe}(\mathrm{CN})_{6}\right]$ aqueous solution, the same experiments were performed with empty (metal-free) CNTs obtained by arc discharge. Similar to the iron-filled CNT experiments, the hollow CNTs also enhance $\mathrm{C} \equiv \mathrm{N}$ modes from $\left[\mathrm{Fe}(\mathrm{CN})_{6}\right]^{4-}$ in solution (Figures S8a and S8b, SI section). However, when chronoamperometry at $1.1 \mathrm{~V}$ is performed, no spectral changes were observed over time, where spectra recorded before and after interfacial polarization remain essentialy the same (Figures S8c and S8d, SI section). These data therefore confirm that the iron species are necessary to electrodeposit PB at the interface under such conditions.

To evaluate the stability and electrochemical performance of the composite, Raman spectroelectrochemical measurements were performed at the $\mathrm{L} / \mathrm{L}$ interface containing the composite film and only $\mathrm{LiCl}$ as supporting electrolyte in the aqueous phase (Figure 8). Raman spectra of the unpolarized interface were acquired prior to experiments, where CNT and PB signals can be observed. The interface was then polarized at 0.0 and $1.0 \mathrm{~V}$. At lower potentials, a decrease of the $\mathrm{PB}$ signals occur due to the loss of $\mathrm{Fe}^{\mathrm{III}}-\mathrm{CN}$ stretching mode, while at higher potentials the signals are intensified. This behavior is assigned to the presence of both $\mathrm{Fe}^{\mathrm{III}}-\mathrm{CN}$ and $\mathrm{Fe}^{\mathrm{II}}-\mathrm{CN}$ modes together with an intensification of the resonance effect observed for PB but not for its reduced form, that is colorless. ${ }^{35,79}$ This study demonstrates that the produced composite is electrochemically active, and PB species can be reduced and reoxidized at the $\mathrm{L} / \mathrm{L}$ interface.

Following deposition, the composite film can be readily transferred to a target substrate, the nature of which may be varied depending on the specific application. In addition, the activity of the composite film at the L/L interface itself opens up the possibility for novel and interesting applications, such as mediated redox processes, selective membranes or even heterogeneous catalysis and sensing through biphasic systems.

\section{Conclusions}

Prussian Blue was successfully deposited at an interface between an aqueous and organic solution using iron-filled CNTs as a template and source of iron for the composite structures. By varying the polarization conditions, mainly by exchange of aqueous electrolyte (a)

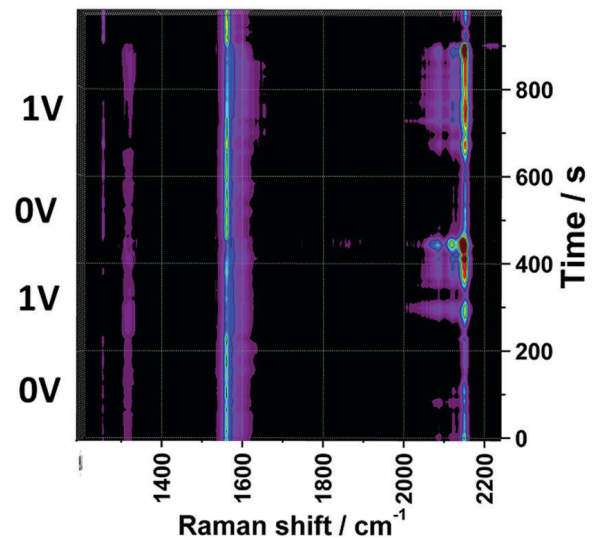

(b)

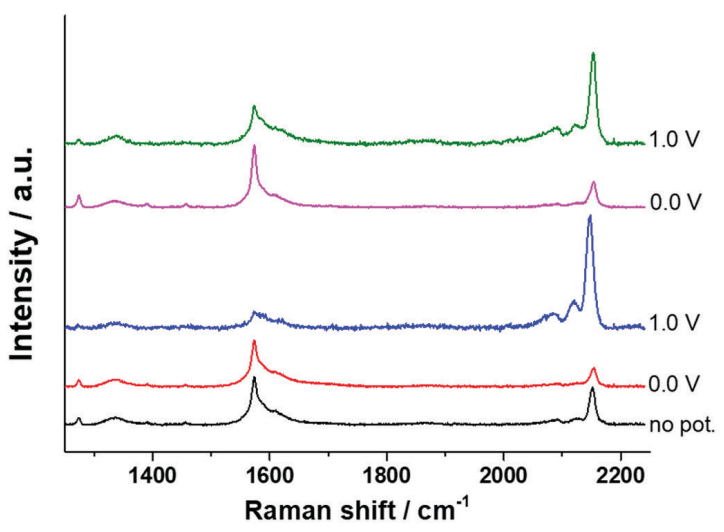

Figure 8. (a) Projection and (b) selected spectra of Raman spectroelectrochemical study performed at a L/L interface containing CNT/PB composite films. The interface was successively polarized at 0.0 and $1.0 \mathrm{~V}$. For this system, the aqueous phase contained $0.1 \mathrm{~mol} \mathrm{~L}-1 \mathrm{LiCl}^{2} \mathrm{pH}$. 
species, PB was formed through the reaction between aqueous species and metal provided by the CNTs. In situ Raman measurements showed CNT doping during PB deposition combined with metal complexation, this was followed by monitoring Raman band shifts. The $\mathrm{CNT} / \mathrm{PB}$ composite formed at the $\mathrm{L} / \mathrm{L}$ interface is stable and electrochemically active, making it suitable for applications following transfer to a desired substrate, but also in situ at the $\mathrm{L} / \mathrm{L}$ interface itself.

\section{Supplementary Information}

Supplementary information (CNT film voltammetry, blank and hollow CNT electrochemical studies, hollow CNT Raman data and optical images of the electrochemical cell) is available free of charge at http://jbcs.sbq.org.br as PDF file. Supporting data files are available from the authors upon request.

\section{Acknowledgments}

We acknowledge the financial support from Brazilian and UK research funding agencies CAPES, CNPq, National Institute of Science and Technology of Carbon Nanomaterials (INCT-Nanocarbono) and EPSRC (grant reference EP/P00119X/1). S. H. thanks CAPES for the sandwich scholarship that facilitated this collaboration.

\section{References}

1. Reymond, F.; Girault, H. H.; Liquid/Liquid Interfaces, Electrochemistry at Encyclopedia of Analytical Chemistry; John Wiley \& Sons: Hoboken, 2006.

2. Dryfe, R. A. W.; Phys. Chem. Chem. Phys. 2006, 8, 1869.

3. Senda, M.; Kakiuchi, T.; Osaka, T.; Electrochim. Acta 1991, $36,253$.

4. Booth, S. G.; Dryfe, R. A. W.; J. Phys. Chem. C 2015, 119, 23295.

5. Monroe, C. W.; Daikhin, L. I.; Urbakh, M.; Kornyshev, A. A.; J. Phys.: Condens. Matter 2006, 18, 2837.

6. Souza, V.; Husmann, S.; Neiva, E.; Lisboa, F.; Lopes, L.; Salvatierra, R.; Zarbin, A. J. G.; Electrochim. Acta 2015, 197, 200.

7. Lin, Y.; Skaff, H.; Emrick, T.; Dinsmore, A.; Russell, T. P.; Science 2003, 299, 226.

8. Dryfe, R. A. W.; Simm, A. O.; Kralj, B.; J. Am. Chem. Soc. 2003, 125, 13014.

9. Domingues, S. H.; Salvatierra, R. V.; Oliveira, M. M.; Zarbin, A. J. G.; Chem. Commun. 2011, 47, 2592.

10. Salvatierra, R. V.; Cava, C. E.; Roman, L. S.; Oliveira, M. M.; Zarbin, A. J. G.; Chem Commun. 2016, 52, 1629.
11. Booth, S. G.; Uehara, A.; Chang, S. Y.; Mosselmans, J. F. W.; Schroeder, S. L.; Dryfe, R. A. W.; J. Phys. Chem. C 2015, 119, 16785 .

12. Johans, C.; Lahtinen, R.; Kontturi, K.; Schiffrin, D. J.; J. Electroanal. Chem. 2000, 488, 99.

13. Platt, M.; Dryfe, R. A. W.; J. Electroanal. Chem. 2007, 599, 323.

14. Johans, C.; Kontturi, K.; Schiffrin, D.; J. Electroanal. Chem. 2002, 526, 29.

15. Gründer, Y.; Ramasse, Q.; Dryfe, R. A. W.; Phys. Chem. Chem. Phys. 2015, 17, 5565.

16. Grunder, Y.; Ho, H. L. T.; Mosselmans, J. F. W.; Schroeder, S. L. M.; Dryfe, R. A. W.; Phys. Chem. Chem. Phys. 2011, 13, 15681.

17. Salvatierra, R. V.; Oliveira, M. M.; Zarbin, A. J. G.; Chem. Mater. 2010, 22, 5222.

18. Mehl, H.; Oliveira, M. M.; Zarbin, A. J. G.; J. Colloid Interface Sci. 2015, 438, 29.

19. Toth, P. S.; Rabiu, A. K.; Dryfe, R. A. W.; Electrochem. Commun. 2015, 60, 153.

20. Toth, P. S.; Velický, M.; Ramasse, Q. M.; Kepaptsoglou, D. M.; Dryfe, R. A. W.; Adv. Funct. Mater. 2015, 25, 2899.

21. Du, J.; Pei, S.; Ma, L.; Cheng, H. M.; Adv. Mater. 2014, 26, 1958.

22. Tan, C.; Tan, K.; Ong, Y.; Mohamed, A.; Zein, S.; Tan, S. In Environmental Chemistry for a Sustainable World; Lichtfouse, E.; Schwarzbauer, J.; Robert, D., eds.; Springer: Dordrecht, 2012, ch. 1.

23. Hu, L.; Hecht, D. S.; Grüner, G.; Chem. Rev. 2010, 110, 5790.

24. Buser, H. J.; Schwarzenbach, D.; Petter, W.; Ludi, A.; Inorg. Chem. 1977, 16, 2704.

25. Itaya, K.; Uchida, I.; Neff, V. D.; Acc. Chem. Res. 1986, 19, 162.

26. Cui, X.; Liu, G.; Lin, Y.; J. Biomed. Nanotechnol. 2005, 1, 320.

27. Vipin, A. K.; Ling, S.; Fugetsu, B.; Carbohydr. Polym. 2014, $111,477$.

28. Fang, B.; Shen, R.; Zhang, W.; Wang, G.; Zhang, C.; Microchim. Acta 2009, 165, 231.

29. Zhai, J.; Zhai, Y.; Wen, D.; Dong, S.; Electroanalysis 2009, 21, 2207.

30. Nossol, E.; Souza, V. H.; Zarbin, A. J. G.; J. Colloid Interface Sci. 2016, 478, 107.

31. Li, Z.; Chen, J.; Li, W.; Chen, K.; Nie, L.; Yao, S.; J. Electroanal. Chem. 2007, 603, 59.

32. Forment-Aliaga, A.; Weitz, R. T.; Sagar, A. S.; Lee, E. J. H.; Konuma, M.; Burghard, M.; Kern, K.; Small 2008, 4, 1671.

33. Zhang, Y.; Wen, Y.; Liu, Y.; Li, D.; Li, J.; Electrochem. Commun. 2004, 6, 1180.

34. Nossol, E.; Zarbin, A. J. G.; Adv. Funct. Mater. 2009, 19, 3980 .

35. Nossol, E.; Zarbin, A. J. G.; J. Mater. Chem. 2012, 22, 1824. 
36. Husmann, S.; Zarbin, A. J. G.; Chem. - Eur. J. 2016, 22, 6643.

37. Husmann, S.; Zarbin, A. J. G.; Dalton Trans. 2015, 44, 5985.

38. Uehara, A.; Chang, S.-Y.; Booth, S. G.; Schroeder, S. L. M.; Mosselmans, J. F. W.; Dryfe, R. A. W.; Electrochim. Acta 2016, 190, 997.

39. Quinn, B.; Lahtinen, R.; Murtomäki, L.; Kontturi, K.; Electrochim. Acta 1998, 44, 47.

40. Cunnane, V. J.; Geblewicz, G.; Schiffrin, D. J.; Electrochim. Acta 1995, 40, 3005.

41. Vanysek, P.; Novák, V.; ECS Trans. 2009, 19, 55.

42. Uehara, A.; Booth, S. G.; Chang, S. Y.; Schroeder, S. L. M.; Imai, T.; Hashimoto, T.; Mosselmans, J. F. W.; Dryfe, R. A. W.; J. Am. Chem. Soc. 2015, 137, 15135.

43. Fermín, D. J.; Duong, H. D.; Ding, Z.; Brevet, P. F.; Girault, H. H.; Electrochem. Commun. 1999, 1, 29.

44. Schnitzler, M. C.; Oliveira, M. M.; Ugarte, D.; Zarbin, A. J. G.; Chem. Phys. Lett. 2003, 381, 541.

45. Cousens, N. E. A.; Kucernak, A. R.; Electrochem. Commun. 2011, 13, 1539.

46. Toth, P. S.; Dryfe, R. A. W.; Analyst 2015, 140, 1947.

47. Hundhammer, B.; Müller, C.; Solomon, T.; Alemu, H.; Hassen, H.; J. Electroanal. Chem. Interfacial Electrochem. 1991, 319 , 125.

48. Niyogi, S.; Hamon, M.; Perea, D.; Kang, C.; Zhao, B.; Pal, S.; Wyant, A.; Itkis, M.; Haddon, R.; J. Phys. Chem. B 2003, 107, 8799.

49. Toth, P. S.; Rodgers, A. N. J.; Rabiu, A. K.; Dryfe, R. A. W.; Electrochem. Commun. 2015, 50, 6.

50. Vanýsek, P.; Basáez Ramírez, L.; J. Chil. Chem. Soc. 2008, 53, 1455.

51. Toth, P. S.; Rodgers, A. N. J.; Rabiu, A. K.; Ibanez, D.; Yang, J. X.; Colina, A.; Dryfe, R. A. W.; J. Mater. Chem. A 2016, 4, 7365.

52. Yu, W.-J.; Hou, P.-X.; Zhang, L.-L.; Li, F.; Liu, C.; Cheng, H.-M.; Chem. Commun. 2010, 46, 8576.

53. Pan, X.; Bao, X.; Chem. Commun. 2008, 6271.

54. Bian, X.; Scanlon, M. D.; Wang, S.; Liao, L.; Tang, Y.; Liu, B.; Girault, H. H.; Chem. Sci. 2013, 4, 3432.

55. Rabiu, A. K.; Toth, P. S.; Rodgers, A. N.; Dryfe, R. A.W.; ChemistryOpen 2016, 6, 57.

56. Rosario-Castro, B. I.; Contés-de Jesús, E. J.; Lebrón-Colón, M.; Meador, M. A.; González-González, I.; Cabrera, C. R.; J. Electroanal. Chem. 2013, 704, 242.

57. Domingo, P. L.; García, B.; Leal, J. M.; Can. J. Chem. 1990, $68,228$.
58. Pharr, C. M.; Griffiths, P. R.; Anal. Chem. 1997, 69, 4673.

59. Wang, L.; Guo, S.; Hu, X.; Dong, S.; Colloids Surf., A 2008 , 317, 394.

60. Chiu, J.-Y.; Yu, C.-M.; Yen, M.-J.; Chen, L.-C.; Biosens. Bioelectron. 2009, 24, 2015.

61. Tirler, A. O.; Persson, I.; Hofer, T. S.; Rode, B. M.; Inorg. Chem. 2015, 54, 10335.

62. Domingo, P. L.; Garcia, B.; Leal, J. M.; Can. J. Chem. 1987, $65,583$.

63. Ašpergěr, S.; Trans. Faraday Soc. 1952, 48, 617.

64. Robin, M. B.; Inorg. Chem. 1962, 1, 337.

65. Wang, Y.; Alsmeyer, D. C.; McCreery, R. L.; Chem. Mater. 1990, 2, 557.

66. Dresselhaus, M. S.; Jorio, A.; Saito, R.; Annu. Rev. Condens. Matter Phys. 2010, 1, 89.

67. Dresselhaus, M. S.; Dresselhaus, G.; Saito, R.; Jorio, A.; Phys. Rep. 2005, 409, 47.

68. Griffith, W.; Turner, G.; J. Chem. Soc. A 1970, 858.

69. Kettle, S. F. A.; Diana, E.; Marchese, E. M. C.; Boccaleri, E.; Stanghellini, P. L.; J. Raman Spectrosc. 2011, 42, 2006.

70. Gaufres, E.; Tang, N. Y. W.; Lapointe, F.; Cabana, J.; Nadon, M. A.; Cottenye, N.; Raymond, F.; Szkopek, T.; Martel, R.; Nat. Photonics 2014, 8, 72.

71. Mueller, N. S.; Heeg, S.; Kusch, P.; Gaufres, E.; Tang, N. Y. W.; Hubner, U.; Martel, R.; Vijayaraghavan, A.; Reich, S.; Faraday Discuss. 2017, 205, 85.

72. Kettle, S. F.; Aschero, G. L.; Diana, E.; Rossetti, R.; Stanghellini, P. L.; Inorg. Chem. 2006, 45, 4928.

73. Lezna, R. O.; Romagnoli, R.; de Tacconi, N. R.; Rajeshwar, K.; J. Phys. Chem. B 2002, 106, 3612.

74. Giorgetti, M.; Guadagnini, L.; Tonelli, D.; Minicucci, M.; Aquilanti, G.; Phys. Chem. Chem. Phys. 2012, 14, 5527.

75. You, Y.; Yu, X.; Yin, Y.; Nam, K.-W.; Guo, Y.-G.; Nano Res. 2015, 8, 117.

76. Zhai, X.; Gao, Z.; Anal. Sci. 2010, 26, 343.

77. Golabi, S. M.; Noor-Mohammadi, F.; J. Solid State Electrochem. 1998, 2, 30.

78. Sumanasekera, G. U.; Allen, J. L.; Fang, S. L.; Loper, A. L.; Rao, A. M.; Eklund, P. C.; J. Phys. Chem. B 1999, 103, 4292.

79. Nossol, E.; Zarbin, A. J. G.; Sol. Energy Mater. Sol. Cells 2013, $109,40$.

Submitted: October 2, 2017 Published online: February 16, 2018 